\title{
Fire Development in Large Tunnel Fires
}

\author{
HAUKUR INGASON \\ Fire Technology \\ SP Swedish National Testing and Research Institute \\ Box 857, SE-501 15 Borås, Sweden
}

\begin{abstract}
The paper gives a quantitative description of the fire development in large tunnel fires and simple analytical expressions to calculate the heat release rate (HRR), time to reach the maximum HRR and the fire duration in fuel-controlled tunnel fires. If knowing the total heat content and the maximum HRR, there will be only one parameter to vary, the parameter $\mathrm{n}$ from the original work by Numajiri and Furukawa [1]. Comparison to experimental data from large-scale tunnel fires is presented in order to see the applicability of the mathematical expressions for tunnel fires. Investigators of large tunnel fire accidents and researchers can use the mathematical expressions given in order to reconstruct the HRR development. These equations can also be applied when there is a need for analytical descriptions of HRR of free burning fires.
\end{abstract}

KEYWORDS: heat release rate (HRR), fire development, large tunnel fires

\section{NOMENCLATURE}

\begin{tabular}{|c|c|c|c|}
\hline E & energy content (kJ) & Greek & \\
\hline$D$ & diameter (m) & $\beta$ & ratio of $E_{t o t, t_{d}} / E_{t o t}$ \\
\hline$k$ & time width coefficient [1] & Subscı & ripts \\
\hline$L_{f}$ & flame length (m), see Fig. 1 & avg & average value \\
\hline 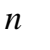 & retard index [1] & c & combustion zone \\
\hline$Q$ & heat release rate - HRR $(\mathrm{kW})$ & $c r$ & critical value \\
\hline$r$ & amplitude coefficient [1] & $d$ & duration \\
\hline$T$ & gas temperature & h & hydraulic \\
\hline 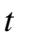 & time (s) & $\max$ & maximum value \\
\hline X & distance (m), see Fig. 2 & tot & total value \\
\hline$u$ & longitudinal ventilation rate $(\mathrm{m} / \mathrm{s})$ & & vaporisation (pyrolysis) \\
\hline
\end{tabular}

\section{INTRODUCTION}

The large tunnel fire accidents that have occurred worldwide, especially in Europe, have placed a focus on fire spread and fire development in tunnels. The need for a better understanding of the fire development in such fires has become apparent. There are several factors that have played a major role in the growth of the large tunnel fires. In road tunnels the high fire load represented by the many Heavy Goods Vehicles (HGV)s involved has been instrumental. Fires involving flammable cargoes in HGVs develop very quickly. In metro systems it has been the fast fire spread between coaches. Other factors are that the ventilation spreads the fire and the rescue services have great difficulty fighting the fire - vision is obscured by smoke, and the enormous heat levels prevent fire fighters from getting to the seat of the fire, even when the smoke is ventilated away. 
Information about the fire development in large tunnel fire accidents is usually very limited and technical information concerning maximum HRRs, time to maximum HRRs or duration of the fire, is uncommon. The information about the amount of combustible material is also limited in many cases. Data concerning the fire duration is usually based on the time when the fire brigade obtained a control of the fire or when the fire was completely extinguished. This information may differ from the actual fire duration i.e., the time period of the fire when the HRR is measurable and not only glowing embers or small flames in the wrecks. This tailing period of the HRR curve may be quite long in large tunnel fires if the fire brigade is not able to intervene.

There is a need to develop a simple mathematical expression, which can be used to describe the HRR development in tunnel fires, both in single vehicles and when the fire spreads to other vehicles. Therefore, a method to describe the HRR based on the maximum HRR $\left(\dot{Q}_{\max }\right)$ or time to reach maximum HRR $\left(t_{\max }\right)$ or fire duration time $\left(t_{d}\right)$ or the total heat content $\left(E_{t o t}\right)$ is presented and applied on some large-scale experimental data.

\section{FIRE DEVELOPMENT IN LARGE TUNNEL FIRES}

In order to understand the fire development in many large tunnel fires we first need to explain how these fires progress. In all large tunnel fire accidents multiple vehicles or coaches are involved. The fire may both start in one vehicle or in two vehicles due to a collision and then spread to the adjacent vehicles largely by radiation from the flames and the hot smoky gases. Rew and Deaves [2] postulated various mechanisms for fire spread based on work concerning the Channel Tunnel Fire in 1996. According to Rew and Deaves the first mechanism is flame impingement. Due to low ventilation rate the flames are deflected by the presence of the ceiling, mainly in the direction of the ventilation flow. The flames visually 'crawl' along the ceiling above the vehicles, see Fig. 1. Rew and Deaves [2] presented a flame length model for tunnels, which included heat release rate and longitudinal velocity but not the tunnel width or height. Much of their work is based on the investigation of the Channel Tunnel Fire in 1996 and test data from the HGV-EUREKA 499 fire test [3] and the Memorial Tests [4]. They defined the horizontal flame length, $L_{f}$, as the distance of the $600^{\circ} \mathrm{C}$ contour from the centre of the HGV or the pool, or from the rear of the HGV, see Fig. 1.

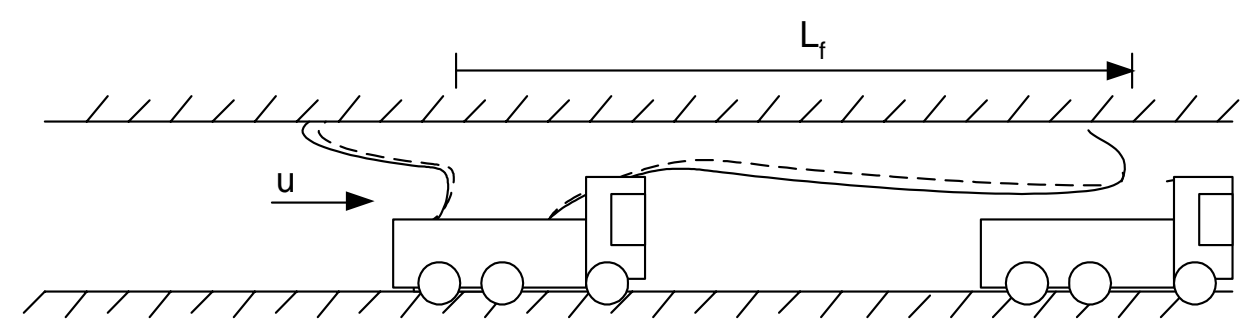

Fig. 1. The flame impimgment mechanism in tunnels with longitudinal flow. The target vehicle is about to ignite and $L_{f}$ is the flame length.

The second one is surface spread, that is to say flame spread across the surface of the fire load. The third is remote ignition (or spontaneous ignition); the conditions at vehicles that are not very close to the initial fire are raised to the point of spontaneous 
ignition due to the high temperatures produced by the fire. The fourth is fuel transfer, since flammable liquids spread from fuel tanks or debris downwind of the fire, or may even according to tunnel slope, flow in opposite direction. The last one is explosion i.e., explosion of fuel tanks may spread burning fuel to adjacent vehicles. In most large tunnel fire accidents that has occurred the mechanism of flame impingement is the one that has been the dominating mechanism of fire spread. Although Rew and Deaves postulate that this mechanism occurs with low ventilation rate, it can also occur in relatively high longitudinal ventilation flow. The most realistic mode of fire spread is, however, the combination of these primary mechanisms.

The critical condition for fire spread in large tunnel fires controlled by the flame impingement fire spread, i.e., ignition of target vehicles, depends on the risk for spontaneous ignition of the target vehicle. The possibility of ignition of the target vehicle can be judged by evaluation of whether or not the exposed surface would attain a critical ignition temperature. The critical temperature, $T_{c r}$, can be estimated as: $600^{\circ} \mathrm{C}$ for radiant exposure and $500^{\circ} \mathrm{C}$ for convective exposure in the case of spontaneous ignition; and, 300 to $410^{\circ} \mathrm{C}$ for radiant exposure and $450^{\circ} \mathrm{C}$ for convective exposure in the case of piloted ignition. Note that these are approximate values, mostly deduced from experiments on small vertical specimens [5].Newman and Tewarson [6] argue that, at ignition, $T_{c r} \approx T_{\text {avg }}$ (the average gas temperature) for duct flow, i.e., when the $T_{\text {avg }}$ has obtained a critical ignition temperature, the material at that location will ignite. This would comply with the flame impingement mode discussed earlier since we know that the flame tip is sometimes defined at $600^{\circ} \mathrm{C}$ isotherm in tunnels [2].

de Ris [7] has shown schematically how fires spread in ducts with combustible wall linings. The description given by de Ris can be applied to the situation with vehicles fires in a road or rail tunnel with longitudinal flow and where fire spreads from one vehicle to the next through flame impingement. Figure 2 shows a schematic description of a large tunnel fire with relatively high forced longitudinal ventilation rate. The burning process can be viewed as stationary and the fire-spread progress can be divided into different key zones [7]:

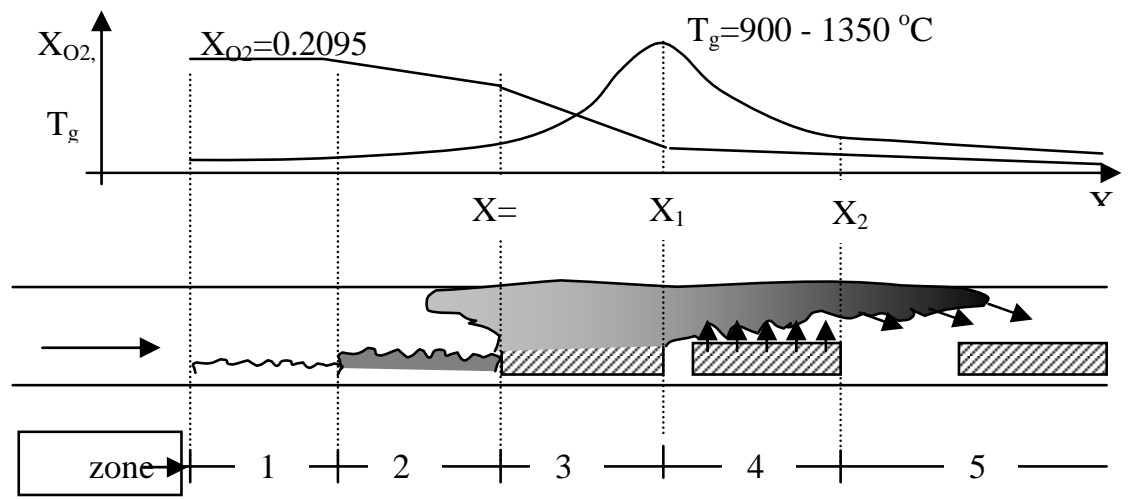

Fig. 2. Schematic presentation of a flame impingement fire spread process in a tunnel with multiple vehicles/coaches.

1) burnt out cooling zone

2) glowing ember zone 
3) combustion zone

4) excess fuel zone

5) preheating zone

Provided there are sufficient vehicles in the vicinity of the initial fire, these different zones move forward in a dynamic manner. The 'burn out zone' involves vehicles that have been completely consumed in the fire and where the fire gases cool down. The 'glowing ember zone' contains vehicles at a very late stage of the decay phase (a pile of glowing embers). The 'combustion zone', which starts at $x=0$ in Fig. 2, contains violently burning vehicles (fully developed fire) where sufficient fuel is vaporising to support gas phase combustion. Flaming combustion is observed throughout this zone. The flames cause large heat transfer rates from the gas to the fuel and consequently large fuel vaporisation rates. The gas phase temperature just beyond $x=0$ increases rapidly. Simultaneously the oxygen is rapidly depleted as the temperature reaches a maximum at $x=x_{1}$, i.e., just beyond the 'combustion zone.' If the oxygen is consumed within the combustion zone, the 'excess fuel zone' starts at $x=x_{1}$. In the case where all the oxygen has been depleted we have a ventilation-controlled fire. In the case where oxygen is still available we have a fuel-controlled fire and no excess fuel (no more vehicles in place to sustain the progress). In the case of ventilation-controlled fire, the fuel continues to vaporise from the vehicles throughout this zone up to a point along the tunnel where the gas stream has cooled to the fuel vaporisation (pyrolysis) temperature $\left(T_{\text {vap }} \geq 300^{\circ} \mathrm{C}\right.$ for the majority of solid materials). Beyond this point, $x=x_{2}$, no vaporisation of the vehicle materials occur but the gas flows into a 'preheating zone' and loses its heat to the tunnel walls and preheats the vehicle material within this zone. de Ris [7] showed that the combustion and excess fuel zone lengths are proportional to the forced ventilation rate when the fire becomes ventilation-controlled and Comitis et al. that the fire will propagate at a constant speed [8] (when ventilation-controlled) provided that there is enough combustible material available. Delichatsios [9] concluded that active burning in a fibreglass-reinforced plastic duct will take place up to a maximum length corresponding to $L_{c} / D_{h}=10$ where $D_{h}$ is the hydraulic diameter of the duct (m) and $L_{c}$ is the combustion length (m). Assuming that this number is reasonable for tunnels the combustion zone, for a ventilation-controlled fire with forced ventilation, would not exceed 50 to $100 \mathrm{~m}$ for most common road and rail tunnels (assuming high vehicle density) where $D_{h}$ is ranging between 5 and $10 \mathrm{~m}$. It is, however, necessary to experimentally investigate the validity of this ratio for road and rail tunnels. This indicates that in the largest tunnel fires such as the one in the Mont Blanc tunnel we may obtain a period with a relatively constant HRR. In other cases, i.e., when the fire is fuel-controlled we may expect a relatively short period with maximum HRR.

\section{METHOD TO DESCRIBE THE HEAT RELEASE RATE DEVELOPMENT}

As can be understood by the nature of these large tunnel fires, it is rather complicated to predict the HRR development. It can be done by accurate analysis of flame spread, flame lengths and by pyrolysis analysis similar to what we discussed earlier. It is, however, not the purpose of this paper to introduce such complicated model. Here the aim is to provide a model to reconstruct the HRR development in large tunnel fires in a realistic and robust way. The key parameters in the model are the total energy content $\left(E_{t o t}\right)$, the maximum heat release rate $\left(\dot{Q}_{\max }\right)$, the time to reach maximum heat release rate $\left(t_{\max }\right)$ and the fire duration $\left(t_{d}\right)$. In order to accomplish this we need to apply a distinctive mathematical 
expression giving the shape of the HRR curve. There are numerous mathematical expressions available in the literature to describe the fire growth part and/or the decay period of the HRR. The HRR is either described as a time dependent power law function $\left(t^{2}, t^{3}\right)$ or as an exponential function $\left(e^{t}\right.$ or $\left.e^{-t}\right)$. None of them are based on derivation from physical processes of combustion or fire spread. If authors want to describe the entire fire development they tend to merge two or three mathematical expressions (e.g., $t^{2}$, constant and $\left.e^{-t}\right)$.

Numajiri and Furukawa [1] presented an excellent paper, which works out the problem of using many mathematical expressions in order to describe a complete fire development. In this paper we will apply and develop the representative equation given by Numajiri and Furukawa of the HRR-curve for Cone Calorimeter data:

$H R R=n \cdot r\left(1-e^{-k \cdot t}\right)^{n-1} \cdot e^{-k \cdot t}$

where HRR is the Heat Release Rate $\left(\mathrm{kW} / \mathrm{m}^{2}\right), t$ the time (min), $r$ the amplitude coefficient, $k$ the time width coefficient and $n$ the retard index. The amplitude coefficient $r$ is a coefficient that is adjusted to equal HRR maximum values obtained from fit function describe by Eq. 1 and in the related experimental curve. The time width coefficient $k$ is a coefficient to adjust the wave width. Numajiri and Furukawa adjusted the $n, r$ and $k$ parameters in a classical spreadsheet software in order to fit to experimental Cone Calorimeter data.

In order to adjust the use of Eq. 1 to the purpose of this paper Eq. 1 has been rewritten in the following way:

$$
\dot{Q}(t)=\dot{Q}_{\max } \cdot n \cdot r \cdot\left(1-e^{-k \cdot t}\right)^{n-1} \cdot e^{-k \cdot t}
$$

where $\dot{Q}_{\max }$ is the maximum HRR in $\mathrm{kW}$ and $t$ is time in seconds. Now it is possible to derive the time to maximum HRR by derivate Eq. 2 and solve for $t_{\max }$ :

$t_{\max }=\frac{\ln (n)}{k}$

If we put $t_{\max }$ into Eq. 2, and put $\dot{Q}(t)=\dot{Q}_{\max }$ we can derive a relationship between $r$ and $n$ :

$r=\left(1-\frac{1}{n}\right)^{1-n}$

This means that we only have to use $n$ to vary the shape of the curve. Now we need to find a relationship between $k$ and the other parameters. If we integrate Eq. 2 from $t=0$ to $t=\infty$ we get the total energy content $E_{\text {tot }}$ or: 
$E_{\text {tot }}=\dot{Q}_{\max } \cdot \frac{r}{k}$

where $E_{\text {tot }}$ is in kJ. Now we can find $k(n)$ with aid of Eqs. 4 and 5:

$k=\frac{\dot{Q}_{\max }}{E_{\text {tot }}} \cdot\left(1-\frac{1}{n}\right)^{1-n}$

If we put Eqs. 4 and 6 into Eq. 2 we have a equation that has only one parameter to adjust $(n)$ instead of three $(n, r, k)$.

$\dot{Q}(t)=\dot{Q}_{\max } \cdot n \cdot\left(1-\frac{1}{n}\right)^{1-n} \cdot\left(1-e^{-\frac{\dot{Q}_{\max }}{E_{\text {tot }}} \cdot\left(1-\frac{1}{n}\right)^{1-n} \cdot t}\right)^{n-1} \cdot e^{-\frac{\dot{Q}_{\max }}{E_{\text {tot }}} \cdot\left(1-\frac{1}{n}\right)^{1-n} \cdot t}$

Here we assume that we can estimate or know in advance $\dot{Q}_{\max }$ and $E_{\text {tot. }}$ Since Eqs. (2) and (7) are infinite in time we are not able to derive any fire duration time without defining a fictive fire duration time, $t_{d}$. In our case it is the time when $E_{\text {tot, } t_{d}} / E_{\text {tot }} \geq \beta$

where $\beta$ is the ratio between the integrated energy at time $t_{d}, E_{\text {tot,td }}$ and the total energy released in the fire. By integrating Eq. 7 from $t=0$ to $t=t_{d}$ and assume that $E_{\text {tot }, t_{d}} / E_{\text {tot }}=\beta$ we can solve for $t_{d}$ :

$t_{d}=\frac{E_{\text {tot }}}{\dot{Q}_{\max }} \cdot\left(1-\frac{1}{n}\right)^{n-1} \cdot \ln \left(\frac{1}{1-\beta^{\frac{1}{n}}}\right)$

where the fire duration is in seconds and the value of $\beta$ can be arbitrarily chosen. Now we are able to reconstruct the fire development using $E_{\text {tot }}, \dot{Q}_{\max }$ and $n$. Eqs. $3-8$ can be used in order to reconstruct large tunnel fire accidents or to make curve fits to experimental data that is available. In the case of large tunnel fire accidents we need to establish the fire duration time, the total energy content and even try to estimate the $\dot{Q}_{\max }$. The only thing left to do is vary the number $n$ in order to obtain a curve which appears to be reasonable.

\section{COMPARISON TO EXPERIMENTS}

We are not able to present any reconstruction of large tunnel fire accidents in this paper but we can demonstrate the use of the equation by compare the results to measured HRR data in large tunnel experiments using single vehicles. There is no large-scale tunnel 
experiments available including fire spread between multiple vehicles. First, we will summaries some large-scale experiments that has been performed in tunnels where we

know of the $E_{\text {tot }}$ and $\dot{Q}_{\max }$.

In Table 1 a list of data from large-scale fire experiments using large vehicles is presented. The first extensive large-scale test series where the HRR and gas temperatures from various large vehicles (passenger cars, train wagons, subway cars and HGV trailer) were measured was in the EUREKA 499 - FIRETUN test series in 1990 to 1992 [3]. The peak HRRs measured varied between 6 and $128 \mathrm{MW}$. The flame length along the ceiling was estimated to be about $37 \mathrm{~m}$ when the fire was $120 \mathrm{MW}$ [2] in the test with a HGV. The final results and all the detailed information from the project were presented in a technical report published in 1995 [3]. In year 2002, a test series was performed in the in the Second Benelux tunnel [13] in the Netherlands. HRR from pan fires (5, $20 \mathrm{MW})$, vehicle fires such as passenger cars, vans and HGV fire load were measured. The measured peak HRR varied between 4.5 and 26 MW. No information is available on flame lengths along the ceiling. In 2003 large-scale tunnel tests were carried out with HGV cargos in the Runehamar tunnel in Norway $[11,14,15,16]$. The tunnel is a two-wayasphalted road tunnel that was taken out of use and is $1600 \mathrm{~m}$ long, $6 \mathrm{~m}$ high and $9 \mathrm{~m}$ wide, with a up and downhill slope $0.45 \%$ and $1 \%$, respectively. The specific commodities used consisted of four different materials, each representing a category of material typically found in the cargo of a HGV-trailer. These commodities were: standardized wood pallets (1200 mm x $800 \mathrm{~mm}$ x $150 \mathrm{~mm})$; plastic pallets made of polyethylene (PE) (1200 mm x $800 \mathrm{~mm}$ x $150 \mathrm{~mm}$ ); a standardized test commodity consisting of polystyrene cups (PS) in compartmented cardboard cartons (600 mm x $400 \mathrm{~mm}$ x $500 \mathrm{~mm}$ ); and polyurethane mattresses (PUR) (1200 mm x $800 \mathrm{~mm}$ x $150 \mathrm{~mm})$. In total four tests were performed. In three tests mixtures of different chosen cellulose and plastic materials were used, and in one test "real" commodity consisting of furniture and fixtures was used. In all tests the mass ratio was approximately $80 \%$ cellulose and $20 \%$ plastic. A polyester tarpaulin covered the cargo. The maximum heat release rates varied between $66 \mathrm{MW}$ and $202 \mathrm{MW}$. The maximum flame lengths for each of the tests were estimated to be in the range of 37 to $93 \mathrm{~m}$ assuming a $600^{\circ} \mathrm{C}$ flame tip. 
Table 1. A summary of large scale tests in tunnels using large road vehicles.

\begin{tabular}{|c|c|c|c|c|}
\hline $\begin{array}{l}\text { Type of vehicle, test series, test } \mathrm{nr} \text {, } \\
u=\text { =longitudinal ventilation } \mathrm{m} / \mathrm{s}\end{array}$ & $\begin{array}{c}\begin{array}{c}\text { Cross- } \\
\text { section }\end{array} \\
\mathbf{m}^{2}\end{array}$ & $\begin{array}{c}\text { Total } \\
\text { heat } \\
\text { content, } \\
E_{t o t} \\
(G J)\end{array}$ & $\begin{array}{l}\text { Max } \\
\text { HRR, } \\
\dot{Q}_{\max } \\
\text { (MW) }\end{array}$ & Reference \\
\hline $\begin{array}{l}\text { A } 25-35 \text { year old } 12 \mathrm{~m} \text { long Volvo } \\
\text { school bus with } 40 \text { seats, EUREKA } \\
499, u=0.3 \mathrm{~m} / \mathrm{s}\end{array}$ & $25-35$ & 41 & 29 & \begin{tabular}{|l} 
Ingason et al. \\
{$[10]$}
\end{tabular} \\
\hline $\begin{array}{l}\text { A trailer load with total } 10.9 \text { ton wood } \\
\left(82 \%^{* *}\right) \text { and plastic pallets }(18 \%) \\
\text { Runehamar test series, Test } 1, u=3 \\
\mathrm{~m} / \mathrm{s}\end{array}$ & $32-47$ & 247 & 202 & $\begin{array}{l}\text { Ingason and } \\
\text { Lönnermark } \\
{[11]}\end{array}$ \\
\hline $\begin{array}{l}\text { A trailer load with total } 6.8 \text { ton wood } \\
\text { pallets(82\%) and PUR mattresses } \\
(18 \%), \text { Runehamar test series, Test } 2, \\
\mathrm{u}=3 \mathrm{~m} / \mathrm{s}\end{array}$ & $32-47$ & 135 & 157 & $\begin{array}{l}\text { Ingason and } \\
\text { Lönnermark } \\
{[11]}\end{array}$ \\
\hline $\begin{array}{l}\text { A Leyland DAF 310ATi - HGV trailer } \\
\text { with } 2 \text { tons of furniture, EUREKA } \\
499, u=3-6 \mathrm{~m} / \mathrm{s}\end{array}$ & $25-35$ & 87 & 128 & \begin{tabular}{|l} 
Grant and \\
Drysdale [12]
\end{tabular} \\
\hline $\begin{array}{l}\text { A trailer with } 8.5 \text { ton furnitures, } \\
\text { fixtures and rubber tyres, Runehamar } \\
\text { test series, Test } 3, u=3 \mathrm{~m} / \mathrm{s}\end{array}$ & $32-47$ & 179 & 119 & $\begin{array}{l}\text { Ingason and } \\
\text { Lönnermark } \\
\text { [11] }\end{array}$ \\
\hline $\begin{array}{l}\text { A trailer mock-up with } 3.1 \text { ton } \\
\text { corrugated paper cartons filled with } \\
\text { plastic cups }(19 \%), \text { Runehamar test } \\
\text { series, Test } 4, u=3 \mathrm{~m} / \mathrm{s}\end{array}$ & $32-47$ & 62 & 67 & $\begin{array}{l}\text { Ingason and } \\
\text { Lönnermark } \\
{[11]}\end{array}$ \\
\hline $\begin{array}{l}\text { A trailer load with } 72 \text { wood pallets, } \\
\text { Second Benelux tests, Test } 14, u=1-2 \\
\mathrm{~m} / \mathrm{s}\end{array}$ & 50 & 19 & 26 & $\begin{array}{l}\text { Lemaire et al. } \\
{[13]}\end{array}$ \\
\hline $\begin{array}{l}\text { A trailer load with } 36 \text { wood pallets, } \\
\text { Second Benelux tests, Test } 8,9 \text { and } 10 \text {, } \\
u=0,4-6 \mathrm{~m} / \mathrm{s} \text { and } 6 \mathrm{~m} / \mathrm{s}\end{array}$ & 50 & 10 & $\begin{array}{l}13,19 \\
\text { and } 16\end{array}$ & \begin{tabular}{|l} 
Lemaire et al. \\
[13]
\end{tabular} \\
\hline $\begin{array}{l}\text { A Simulated Truck Load (STL), } \\
\text { EUREKA 499, } u=0.7 \mathrm{~m} / \mathrm{s}\end{array}$ & $25-35$ & 65 & 17 & \begin{tabular}{|l} 
Ingason et al. \\
{$[10]$}
\end{tabular} \\
\hline
\end{tabular}


On next page comparison is made with few of the tests given in Table 1. In Fig. 3, comparisons are made with four of the tests performed in the Runehamar tunnel 2003. These tests included HGV fire load and more information can be found in reference $[11,14,15,16]$. Other tests are from the Eureka program [3] and the Benelux tunnel [13]. The choice of $n$ was made to make best fit to the experimental data. Eq. 7 was used and the input values were the $\mathrm{E}_{\text {tot }}$ and $\dot{Q}_{\max }$ values in Table 1 . As can be seen the shape of the curves fits convincingly well to the experimental data. This indicates that the mathematical expressions reflect reasonably well the physical process of the fire development for this type of fuel although they were not originally obtained from any such analysis. It is very easy to do this in a classical spreadsheet software in order to find a appropriate fit to the curves. It can also be seen that the fire duration, $t_{d}$, assuming
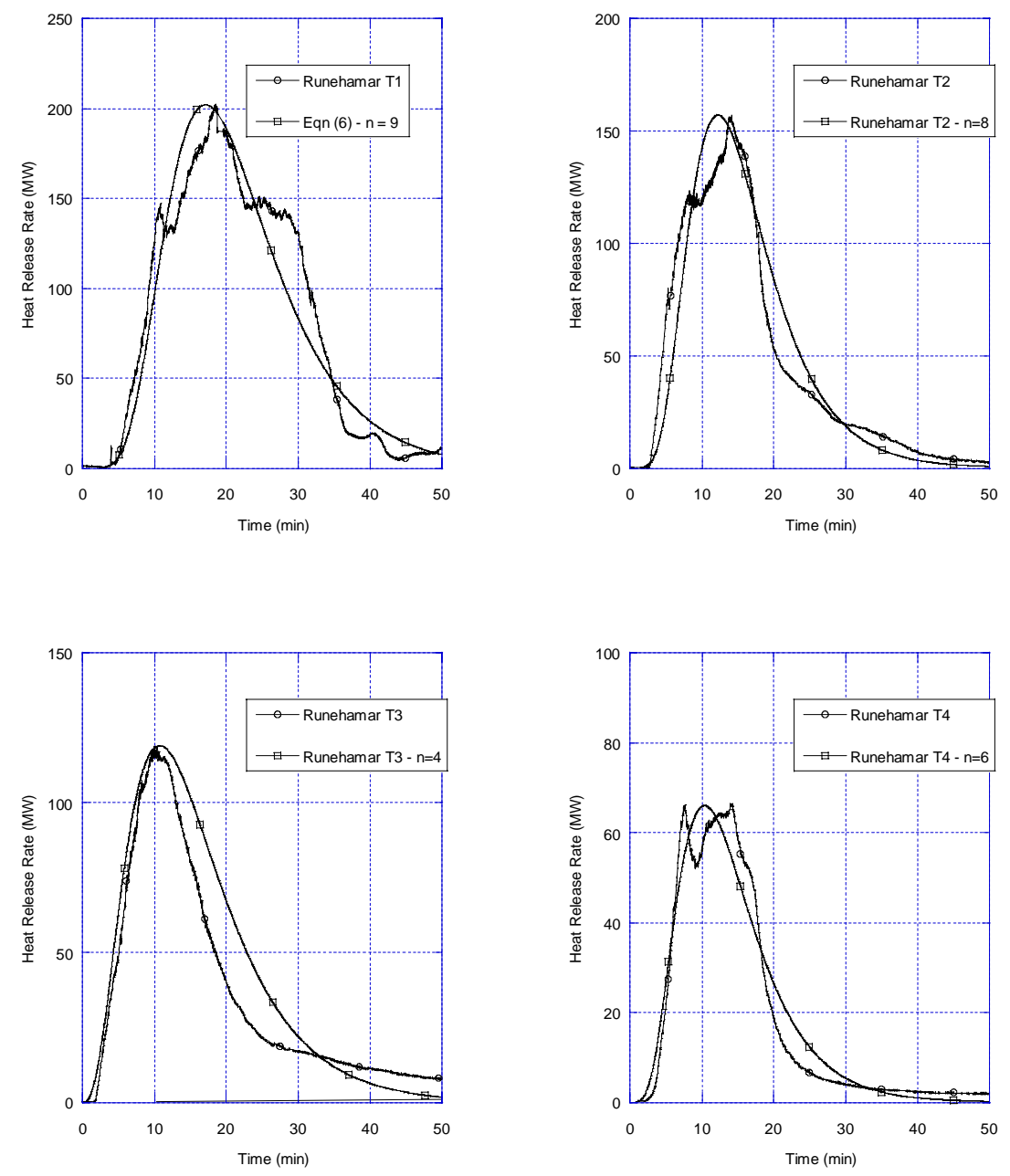

Fig. 3. Comparison to the Runehamar tests [11]. 
$\beta=0.97$, i.e., over $97 \%$ of the energy has been released gives reasonable values. This means that using these equations should be a powerful tool for investigators of tunnel fire accidents when trying to reconstruct the fire development. These equations can be improved for other type of fires, e.g., fires with longer peak period such as in a ventilation-controlled enclosure or tunnel fires. This type of procedure can be done by adding up the basic equation, similar to as Numajiri and Furukawa [1] did in their original work.
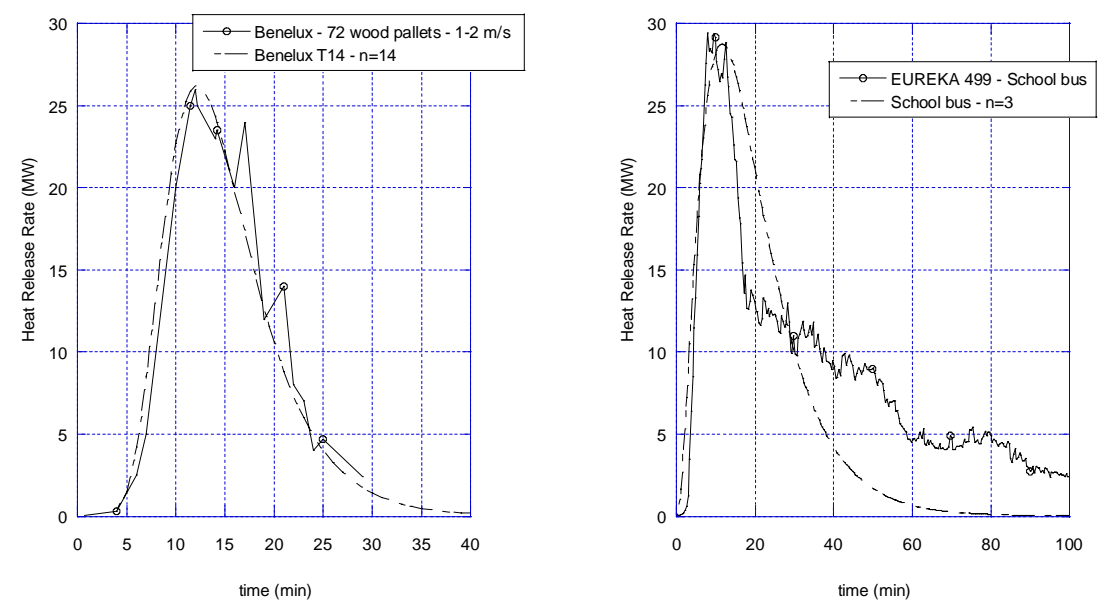

Fig. 4. Comparison to Benelux test (T14) [13] and a bus test carried out in the EUREKA project [3].

\section{CONCLUSIONS}

The paper gives a quantitative description of the fire development in large tunnel fires in order to explain the characteristic of large tunnel fires. From that simple analytical expressions to calculate the heat release rate (HRR), time to reach the maximum HRR and the fire duration in fuel-controlled tunnel fires were developed. Comparison to experimental data from large-scale tunnel fires shows that these equations can be easily used in order to reconstruct vehicle fires in tunnels. The overall compliance of the HRR mathematical expression to the experimental data is reasonably good.

It is postulated that these equations can also be used for other type of fires where we can expect relatively short period of maximum heat release rates. In most tunnel fires we would expect fuel-controlled fires with relatively short maximum period. Exception is extremely large tunnel fires such as the one in the Mont Blanc tunnel where one would expect that the fire was ventilation-controlled during a relatively long period. These mathematical expressions can be easily extended for that type of fires.

Investigators of large tunnel fire accidents can use the mathematical expressions given in order to reconstruct the fire development. These equations can also be applied when there is a need for analytical descriptions of HRR of free burning fires. 


\section{REFERENCES}

[1] Numajiri, F., och Furukawa, K., Short Communication: "Mathematical Expression of Heat Release Rate Curve and Proposal of Burning Index," Fire and Materials, Vol. 22, 39-42 (1998).

[2] Rew, C. and Deaves, D., "Fire Spread and Flame Length in Ventilated Tunnels, a Model Used in Channel Tunnel Assessments," Proceedings of Tunnel Fires and Escape from Tunnels, Lyon, 5-7 May 1999, p. 385-406.

[3] EUREKA 499, Fires in Transport Tunnels: Report on Full-Scale Test. EUREKA-Project EU499: FIRETUN Studiensgesellschaft Stahlanwendung e.V. D-40213 Dusseldorf 1995.

[4] Memorial Tunnel Fire Ventilation Test Program - Test Report - Massachusetts Highway Department and Federal Highway Administration, November 1995.

[5] Kanury, A.M., Flaming Ignition of Solid Fuels, The SFPE Handbook of Fire Protection Engineering, Second Edition, Section 2/Chapter 13, p. 2-201.

[6] Newman, J. and Tewarson, A., "Flame Propagation in Ducts," Combustion and Flame, 51: 347-355 (1983)

[7] de Ris J., "Duct Fires,” Combustion and Science Technology, Vol. 2, pp. 239258 (1970).

[8] Comitis, S.C., Glasser, D., and Young B.D., "An Experimental and Modeling Study of Fires in Ventilated Ducts, Part II: PMMA and Stratification,” Combustion and Flame, 104:138-156, (1996).

[9] Delichatsios M.A., Fire Protection of Fibreglass-reinforced Plastic Stacks in Ducts, Factory Mutual Systems, Report RC75-T-51, File, Serial No. 22493, October 1975.

[10] Ingason, H., Gustavsson, S., and Dahlberg, M., "Heat Release Rate Measurements in Tunnel Fires,” SP Report 1994:08, Swedish National Testing and Research Institute.

[11] Ingason, H. and Lönnermark, A., "Heat Release Rates from Heavy Goods Vehicles Trailers in Tunnels," Fire Safety Journal, (accepted for publication).

[12] Grant, G.B. and Drysdale, D.D., "Estimating Heat Release Rates from Largescale Tunnel Fires," Fire Safety Science, Proceedings of the Fifth International Symposium, pp. 1213-1224.

[13] Lemaire, A., Van De Leur, P.H.E., and Kenyon, Y.M., Safety Proef: TNO Metingen Beneluxtunnel Meetrapport, TNO-Rapport, 2002-CVB-R05572

[14] Lönnermark, A. and Ingason, H., "Gas Temperatures in Heavy Goods Vehicle Fires in Tunnels," Fire Safety Journal, (accepted for publication).

[15] Lemaire, T., "Runehamar Tunnel Fire Tests: Radiation, Fire Spread and Back Layering," International Symposium on Catastrophic Tunnel Fires (CTF), SP Swedish National Testing and Research Institute, Borås, Sweden, 2003. 
[16] Brandt, A., "Presentation of Test Result from Large Scale Fire Tests at the Runehamar Tunnel," International Symposium on Catastrophic Tunnel Fires (CTF), H. Ingason, (ed.), SP Swedish National Testing and Research Institute, Borås, Sweden, 2003. 